late; that residual excesses of fertility and the demographic momentum of bottom-heavy population pyramids will double our numbers by 2050 . Some argue that heroic (draconian?) measures are needed to control fertility now; that, in a world in which $40 \%$ of total photosynthetic production is already used or preempted by Homo sapiens, we cannot double the population without endangering the world's ecological fabric. ${ }^{12}$ India, with 0.9 billion people, has cleared most of its forests; can it support, sustainably, next century's projected 1.8 billion?

Health is at the "soft" end of the population debate. Politicians and their economist advisers focus on the impacts of market, economic growth, control of migration, national security, and the preservation of environmental amenity. In such company (all dressed up in the fashionable terminology of "sustainability") impact on health seems like a poor cousin. Yet this seriously underestimates the importance of ecological sustainability to human health. The biosphere is more than an economist's assemblage of straight line projections and discounted futures. It is a complex of ecosystems and physicochemical cycles that, if unsustained, could not fulfil the productive, cleansing, and protective functions on which life depends.

The Cairo conference must therefore recognise that sustaining human health is a prime reason for concern about population growth (and models of economic development). We have reached an unfamiliar crossroads. Looking back, we can agree that demographic and economic growth over recent centuries has been accompanied by substantial health gains. However, such capital eroding gains, amplified by population growth, cannot continue indefinitely within the essentially closed system that we inhabit.

A J McMICHAEL

Professor of epidemiology

Department of Epidemiology and Population Sciences,

London School of Hygiene and Tropical Medicine,

London WC1 7HT

1 Malthus TR. An essay on the principle of population. New York: Penguin Books, 1970.

2 Kendall HW, Pimentel D. Constraints on the expansion of the global food supply. Ambio 1994;23:198-205.

3 McMichael AJ. Planetary overload: global environmental change and the health of the human species. Cambridge: Cambridge University Press, 1993.

4 Hardoy JE, Mitlin D, Satterthwaite D. Environmental problems in third world cities. London Earthscan, 1992.

5 Acheson ED. Edwin Chadwick and the world we live in. Lancet 1990;236:1482-5.

6 Last JM. Global change: ozone depletion, greenhouse warming and public health. Annu Rev Public Health 1993;14:115-36.

7 World Health Organisation. Potential health effects of climatic change. Repon of a WHO task group. Geneva: WHO, 1990. (WHO/PEP/90/10.)

8 McMichael AJ. Global environmental change and human population health: a conceptual and scientific challenge for epidemiology. Int $₹$ Epidemiol 1993;22:1-8.

9 Unicef. The state of the world's children 1994. Oxford: Oxford University Press, 1994

9 Unicef. The state of the world's children 1994. Oxford: Oxford Un
10 King M. Health is a sustainable state. Lancet 1990;336:664-7.

1 World Bank. World development report 1993. Investing in health. Oxford: Oxford University Press, 1993.

12 Vitousek PM, Ehrlich PR, Ehrlich AH, Matson PA. Human appropriation of the products of photosynthesis. Bioscience 1986;36:368-73.

\title{
Coronary artery disease and women
}

\section{Fustifies equal opportunity management}

Coronary artery disease is now the commonest cause of death in women in many countries, including Britain and the United States. ${ }^{1}$ Its incidence increases with age, rising rapidly after the menopause ${ }^{2}$ : by 65 cardiovascular disease is equally common in men and women. As the proportion of older women in the population increases so the incidence of cardiovascular disease will increase. In the United States cardiovascular disease now kills proportionately more women than men. ${ }^{3}$ Before the age of 65 coronary artery disease is half as common in women as men, affecting affecting one in nine women aged 45 to 64 . But coronary artery disease also affects premenopausal women - a quarter of the deaths from myo-cardial infarction in women under 65 occur in women under 45 .

The first hurdle in assessing coronary artery disease in women is to increase awareness of its existence-both among doctors and among women themselves. Women with coronary artery disease usually present differently from men. ${ }^{4}$ They present more commonly with angina than infarction. Furthermore, their symptoms are more likely to have atypical features and are more often attributed to non-cardiac causes-especially in younger women, in whom coronary artery disease is uncommon. Exercise testing is as useful in women as men when they are aged 65 or over (when the incidence of coronary artery disease is the same), but in younger women, with a lower incidence of coronary artery disease, the rate of false positive results is likely to be higher. (This may explain the finding that women with chest pain are five times more likely to have normal coronary arteries than men. ${ }^{56}$ )

Assessing chest pain in women, Sullivan et al confirmed the limited value of exercise testing in predicting coronary artery disease in women compared with men: they found that it had a sensitivity of $76 \%$ and a specificity of $71 \%$ (95\% and $93 \%$ for men). ${ }^{7}$ Thallium scintigraphy increases the sensitivity and specificity, but breast tissue overlying the heart may erroneously suggest an area of hypoperfusion. Coronary arteriography is as accurate in men and women and remains the stan-dard. With a complication rate of less than one in 5000, it allows the safe optimisation of treatment, especially in younger patients.

\section{Worse treatment for women?}

Do women receive the same treatment as men? Findlay et al identified little sex bias in the referral of patients for revascularisation ${ }^{4}$ and Lincoff $e t$ al noticed that the effectiveness of thrombolysis did not differ between men and women, though women were at greater risk of haemorrhagic stroke. ${ }^{8}$ They noted, however, that the clinical outcome in women was worse, with more reinfarctions and deaths. The women were older and had more complicating factors such as diabetes, and these factors rather than their sex may have been the reason.

In this week's journal Clarke and colleagues report that women do not receive the same treatment as men after acute myocardial infarction (p 563). ${ }^{9}$ Women took slightly longer to reach hospital, perhaps reflecting their lack of awareness of the possibility of infarction. In common with other investigators, the authors observed that women have more severe infarcts and are older at presentation and are therefore more likely to have severe coronary artery disease, which increases their mortality. 
Clarke and colleagues' observation that patients with the highest mortality (elderly women) do not receive thrombolysis or coronary angioplasty may reflect a local policy of not giving thrombolysis outside the coronary care unit and be determined by the unit's policy concerning age rather than by sex bias. This suspicion is reinforced by the similar rates of thrombolysis for men and women once they had been admitted to the coronary care unit. Wilkinson et al report similar findings, confirming the likelihood of more severe disease in women at presentation (significantly more patients with diabetes, hypertension, and heart failure) (p 566). ${ }^{10}$ All patients in their study were admitted to a coronary care unit where the rates of thrombolysis in men and women were not significantly different. In both studies $\beta$ blockers were prescribed significantly less commonly for women, but medical exclusions (for example, heart failure or diabetes) rather than sex bias may explain this. Data on the use of angiotensin converting enzyme inhibitors would be interesting: was this more common in women (reflecting larger infarct size) and did this offset the less frequent use of $\beta$ blockade?

Both studies eliminated age bias as the only explanation for the differences in management and outcome, whereas Hannaford et al suggest that increasing age, not sex, explains the discrepancies in the use of thrombolysis ( $p$ 573). ${ }^{11} \mathrm{~A}$ recent prospective study evaluating sex bias in the referral of patients for cardiac catheterisation did not identify sex as an independent predictor of further investigation and found no evidence that doctors were underestimating the risk of coronary artery disease in women-the difference in referral was related to a lower rate of exercise tests giving a positive result in women rather than to sex alone. ${ }^{12}$ Such prospective studies are helpful but reflect the care of an "aware" group of cardiologists, who may be trying hard to avoid bias.

Different figures emerge from the survival and ventricular enlargement study of captopril after infarction: even though the incidence of angina was the same in both sexes, twice as many men than women had angiography and coronary artery bypass grafting. ${ }^{13}$ Other studies have shown that men with abnormal thallium scans were 10 times more likely than women to have angiography and for a given coronary lesion were four times more likely to undergo coronary artery bypass grafting. ${ }^{14}$

\section{Different risk factors}

Sexual bias may explain these discrepancies, but they could also reflect the influence of other factors: women tend to be older and more commonly have hypertension, diabetes, and cardiac failure. Some of the perceived sexual bias may therefore reflect good clinical judgment and individualised care. Do risk factors differ between women and men? Hypertension seems a stronger risk factor for coronary artery disease in women than men, and diabetes neutralises the survival advantages women have over men up to the age of 65 . Hyperlipidaemia must be looked for when ischaemia is suspected, especially in older women, who lose the protective higher concentrations of high density lipoprotein cholesterol postmenopausally. It is especially important in younger women not to manage on total cholesterol concentration alone as reducing high density lipoprotein by blindly treating total cholesterol could be counterproductive.

Smoking is increasing in (especially younger) women and may reflect social and work stresses combined with clever and carefully targeted advertising. ${ }^{15}$ Women also use cigarette smoking as an aid to control their weight: being thin is fashionable. The effect is dose dependent: premenopausal smokers have three times the rate of infarction of non-smokers; women smoking more than 40 cigarettes a day increase their risk 20 -fold. The combination of smoking and diabetes is particularly hazardous. Newer oral contraceptives containing relatively low doses of oestrogen do not apparently increase the risk of coronary artery disease, but oral contraceptive users should be firmly advised not to smoke.

\section{Hormones could halve risk}

Epidemiological studies have suggested that oral postmenopausal oestrogen treatment halves the risk of coronary artery disease. ${ }^{16}$ Worries that hormone replacement therapy may increase the risk of breast cancer seem unfounded, though its use in women with a strong family history of breast cancer is probably unwise. The main. problem with hormone replacement therapy is the lack of prospective scientific studies-no randomised intervention trials have been performed-and the absence of any effect on total mortality in the observational studies available. Thus healthy women of higher social class with lower cardiovascular risk may select themselves for hormone replacement therapy, which may distort any benefit perceived to be due to use of oestrogen. ${ }^{17}$ Randomised controlled trials are therefore needed to settle the matter (as overall mortality is unaffected). The randomised trial of the National Institutes of Health will not be reported for 14 years but we need a practical management policy now as the potential for halving the incidence of coronary artery disease is difficult to ignore.

Women with coronary artery disease have a higher mortality after infarction and a higher operative risk at the time of coronary artery bypass grafting or angioplasty. The differences probably reflect the more advanced nature of coronary artery disease at presentation combined with naturally smaller coronary arteries. The clinical and angiographic success of angioplasty is now as good for women as men, and though women have twice the mortality from coronary artery bypass grafting men the risk remains small. After coronary artery bypass grafting men and women have the same five year and 10 year survival rates. Women presenting with angina have a better prognosis than men with angina, ${ }^{18}$ which is probably due to the increased incidence of normal coronary arteries in women.

Once diagnosed as having coronary artery disease, women are less likely to be referred or attend for rehabilitation, and they experience more depression, anxiety, and guilt. Rehabilitation courses specifically tailored to the different needs of women are required.

Women are different-but not that different. Although women with coronary artery disease may be more difficult to diagnose and manage than men it is a challenge that we and they must rise to. An equal opportunity killer needs equal opportunity management.

GRAHAM JACKSON

Guy's Hospital,

Consultant cardiologist

London SE1 9RT

1 Wenger NK, Speroff L, Packard B. Cardiovascular health and disease in women. N Engl J Med 1993;329:247-56.

2 Lerner DJ, Kannel WB. Patterns of coronary disease morbidity and mortality: a 26 year follow-up of the Framingham population. Am Heart J 1986;III:383-90.

3 American Heart Association 1993 heart and stroke fact statistics. Dallas, Texas: AHA, 1993: $1-18$.

4 Findlay IN, Cunningham D, Dargie HJ. The rights of woman. Br Heart J 1994;71:401-3.

5 Sketh MH, Mohiuddin SM, Lynch JD, Zencka AE, Runco V. Significant sex differences in the correlation of electro-cardiographic exercise testing and coronary arteriograms. Am J Cardiol 1975;36:169-73. 
6 Weiner DA, Ryan TJ, McCabe CH, Kennedy JW, Schloss M, Tristani F, et al. Exercise stress testing: correlations among history of angina, ST segment response and prevalence of coronary artery disease in the coronary artery surgery study (CASS). N Engl J Med 1979;301:230-5

7 Sullivan AK, Holdright DR, Wright CA, Sparrow JL, Cunningham D, Fox KM. Chest pain in women: clinical, investigative and prognostic features. BMJ 1994;308:883-6.

8 Lincoff AM, Califf RM, Ellis SG, Sigmon KN, Lee KL, Leimberger JD, for the Thrombolysis and Angioplasty in Myocardial Infarction Study Group. Thrombolytic therapy for women with myocardial infarction: is there a gender gap? J Am Coll Cardiol 1993;22:1780-7.

9 Clarke KW, Gray D, Keating NA, Hampton JR. Do women with acute myocardial infarction receive the same treatment as men? $B M J$ 1994;309:563-6.

10 Wilkinson P, Laji K, Ranjadayalan K, Parsons L, Timmis AD. Acute myocardial infarction in women: survival analysis in first six months. BMJ 1994;309:566-90.

11 Hannaford PC, Kay CR, Ferry S. Agism as explanation for sexism in provision of thrombolysis. BMJ 1994; 309: 573 .

12 Mark DB, Shaw LK, Delong ER, Califf RM, Pryor DB. Absence of sex bias in the referral of patients for cardiac catheterisation. N Engl J Med 1994;330:1101-6.
13 Pfeffer MA, Braunwald E, Moye LA, Basta L, Brown Jr EJ, Cuddy TE, et al Effect of captopril on mortality and morbidity in patients with left ventricular dysfunction after myocardial infarction: results of the survival and ventricular enlargement trial. N Engl J Med myocardial infarction

14 Tobin JN, Wassertheil-Smoller S, Wexler JP, Steingart RM, Budner N, Lense L, et al. Sex bias in considering coronary bypass surgery. Ann Intern Med 1987;107:19-25.

15 Warner KE, Goldenhar LM, McLaughlin CG. Cigarette advertising and magazine coverage of the hazards of smoking. N Engl J Med 1992;326:305-309.

16 Stampfer MJ, Colditz GA, Willett WC, Manson JE, Rosner B, Speizer FE, et al. Post menopausal oestrogen therapy and cardiovascular disease: ten year follow-up from the nurses' health study. N Engl J Med 1991;325:756-62.

17 Posthuma WFM, Westendorp RGJ, Vandenbroucke JP. Cardioprotective effect of hormone replacement therapy in postmenopausal women: is the evidence biased? BMJ 1994;308:1268-9.

18 Murabito JM, Evans JC, Larson MG, Levy D. Prognosis after the onset of coronary heart disease. An investigation of differences in outcome between the sexes according to initial coronary disease presentation. Circulation 1993;88:2548-55.

\section{Sick doctors}

\section{$A$ responsibility to act}

What if a consultant pathologist, working largely single handedly and responsible for reading all the specialised histological slides in a large group of hospitals, had manic depression and was prone to periodic bouts of mania that made him skim through large numbers of slides with only cursory scrutiny of them? Who would recognise that there was a problem? What action would be taken? Where would he be treated? When would the decision be taken that it was safe to allow him to return to work? Should there be continuing supervision, and how should it be organised?

This hypothetical example shows only some of the complex questions posed when doctors become ill or are known to be at risk of illness. Many perspectives can be adopted when the phenomenon of the sick doctor is considered: the need to protect patients, the duty of other doctors to report problems, the responsibility of a good employer to care for its staff, the legitimacy given to some types of chronic illness (for example, rheumatoid arthritis) and not to others (for example, drug and alcohol misuse), and whether doctors should be regarded as special cases or just like other employees.

It has long been recognised that doctors, as an occupational group, experience excess mortality from some causes, particularly suicide and self injury, poisoning, and cirrhosis of the liver. ${ }^{1}$ Reviews of morbidity among doctors have suggested a relatively high occurrence of psychiatric and stress related disorders as well as drug and alcohol misuse. ${ }^{23}$

A study carried out under the auspices of the Nuffield Provincial Hospitals Trust set out to explore perceptions of and attitudes to sick doctors as well as the provision of services for them in eight health service localities (p 561).45 The messages from the interviewees (senior and junior doctors, health service managers, industrial relations officers, and representatives of community health councils) were that doctors' health problems are poorly dealt with, interventions come too late, and appreciable attitudinal and organisational barriers exist to the uptake of services. Respondents' views on why help is not sought encompassed the stigmatising nature of illness for doctors (and consequent denial), misguided professional loyalty, attitudes formed during medical training, the perceived irrelevance of services (particularly occupational health services), and a tradition of self treatment and direct self referral to hospital consultants.

The main ways of helping sick doctors currently lie within a series of national procedural frameworks and with local health services: the health committee of the General Medical Council, the National Counselling Service for Sick Doctors, the hospital based mechanism for preventing harm to patients (known as the "three wise men" procedure), ${ }^{6}$ and, for general practitioners, a similar mechanism based on local medical committees. In addition, at local level, occupational health services and general health services have a role. In some places special initiatives have been developed. For example, a "house call" scheme run by a department of psychotherapy in association with the postgraduate dean provides confidential counselling and support for junior hospital doctors who are stressed or distressed. ${ }^{7}$

\section{Doctors should seek help early}

The Nuffield study draws attention to the weaknesses of present procedures and services. It calls for widespread change, with an emphasis on encouraging doctors to behave more like other patients and to seek help early through conventional referral mechanisms. A much greater role is envisaged for general practice and stronger occupational health services.

Although we must accept the criticism that existing procedures are patchy and not well known or understood, we should remember that they are regularly used. Indeed, these formal mechanisms have been the only systematic and serious attempt to deal with the problem of sick doctors. Involvement of the General Medical Council has the drawback that it is defined in statute and is strictly speaking limited to doctors who are severely impaired. Moreover, some doctors are intimidated by the council's disciplinary connotations. The General Medical Council has, however, considerably widened its remit and taken important steps forward in dealing with sick doctors, particularly under the recently retired chairman of its health committee. ${ }^{8}$ Consequently, the council's health committee has played an invaluable part, particularly in respect of rehabilitating sick doctors, ${ }^{9}$ one of the most difficult aspects to deal with. Similarly, the National Counselling Service for Sick Doctors offers an informal route for referral and is dealing with a rising number of cases (currently some $300-400$ a year). ${ }^{10}$

The three wise men procedure, in which a panel of consultants in a hospital has the power to intervene when patients are at risk of harm because of a doctor's illness, is often criticised as ineffective and not widely known. This is 